\title{
Imagem e etnografia: a busca constante do outro
}

\author{
Maria Cristina Castilho Costa \\ Doutora em Ciências Sociais pela FFLCH-USP, livre-docente em Ciências da Comunicação \\ pela ECA-USP, bolsista de produtividade pelo CNPq e autora do livro Educação, imagem \\ e mídias, da Editora Cortez. \\ E-mail: criscast@usp.br
}

Resumo: O texto trata da expansão do europeu pelo mundo a partir da Modernidade e do desenvolvimento das ciências, da tecnologia e das comunicações, para a exploração do distante e do diferente. Mostra como os cientistas sociais desenvolveram um método importante de ver e descrever o outro - a etnografia -, capaz de aproximar pesquisador e objeto de pesquisa, desvendando-os mutuamente. Analisa como a imagem passou a fazer parte desse método de conhecimento e a importância que ela adquire, na atualidade, nas formas contemporâneas de nos relacionarmos e conhecermos o outro.

Palavras-chave: identidade, alteridade, etnografia, imagem, modernidade.
Abstract: The paper discusses the expansion of the European through the world as from the Modernity and the development of sciences, technology and communication, to explore distances and diversities. It shows how social scientists have developed a significant method to see and describe the other - the ethnography - that is capable to approximate the researcher to the research subject, mutually revealing them. It analyses how the image has become part of this knowledge method and the relevance it acquires nowadays in the contemporary forms of relation with the other.

Keywords: identity, alterity, ethnography, image, modernity.

O homem moderno se caracterizou pela mobilidade, curiosidade, expansionismo e ousadia - rompendo com os laços que o prendiam ao lugar de origem, geográfico e social; dedicou-se à busca constante por novos espaços e experiências. Isso o levou às grandes navegações, às descobertas e exploração de novos continentes, ao desenvolvimento do comércio à guerra e à ciência. Uma nova ordem social se organizou e se impôs no Ocidente - nova dimensão do espaço-tempo alargando os horizontes da vida social. O homem moderno foi impulsionado a atravessar oceanos, a enfrentar o diferente, a perceber a amplitude e a diversidade do planeta que habitava. Um crescente nomadismo disseminou populações pelas mais diferentes direções e regiões, em busca de riquezas, prosperidade e novos modelos de vida. As Colunas de Hércules ${ }^{1}$ que, desde a Antiguidade, representavam os limites impostos ao homem pelos deuses, foram definitivamente ultrapassadas. $\mathrm{O}$ contato com o diferente, com o não

Recebido: 20.11.2009

Aprovado: 03.12.2009

1. Colunas de Hércules é o nome dado ao promontório existente no Estreito de Gibraltar, separando a África da Europa e o Mar Mediterrâneo do Atlântico. A origem desse nome remonta à mitologia grega. 
familiar, impôs nova noção de alteridade mesclada por exotismo, preconceito e encantamento.

A história do século XV e XVI na Europa foi marcada pelo desvelamento do outro em termos geográficos e humanos. Trocas comerciais, simbólicas e sociais passam a se realizar de forma incessante. Entre os europeus alarga-se a consciência de si mesmos e dos outros, impõe-se nova concepção de mundo e nova percepção visual da realidade. E assim, como se passa a questionar as explicações religiosas sobre o universo, se desenvolvem a ciência e o racionalismo.

A necessidade de conhecimento sobre o novo impulsiona os relatos que, por sua vez, repercutem favoravelmente na Europa, atraindo leitores, viajantes, comerciantes e monarcas. Entretanto, as palavras pareciam limitadas diante de um mundo que se abria a uma insuspeitada visualidade, daí a necessidade de incluir nas expedições comerciais e científicas desenhistas, pintores e gravadores com a função de descrever visualmente o mundo recém-descoberto ou achado.

Esse processo acabou por estimular, certamente, os experimentos que resultaram na descoberta da fotografia, que dotou o homem moderno de um meio cada vez mais eficaz de registrar suas experiências visuais e sua relação com o outro. Assim, podemos afirmar que a fotografia veio coroar esse movimento civilizatório de desvendamento do diferente e de trânsito de informações.

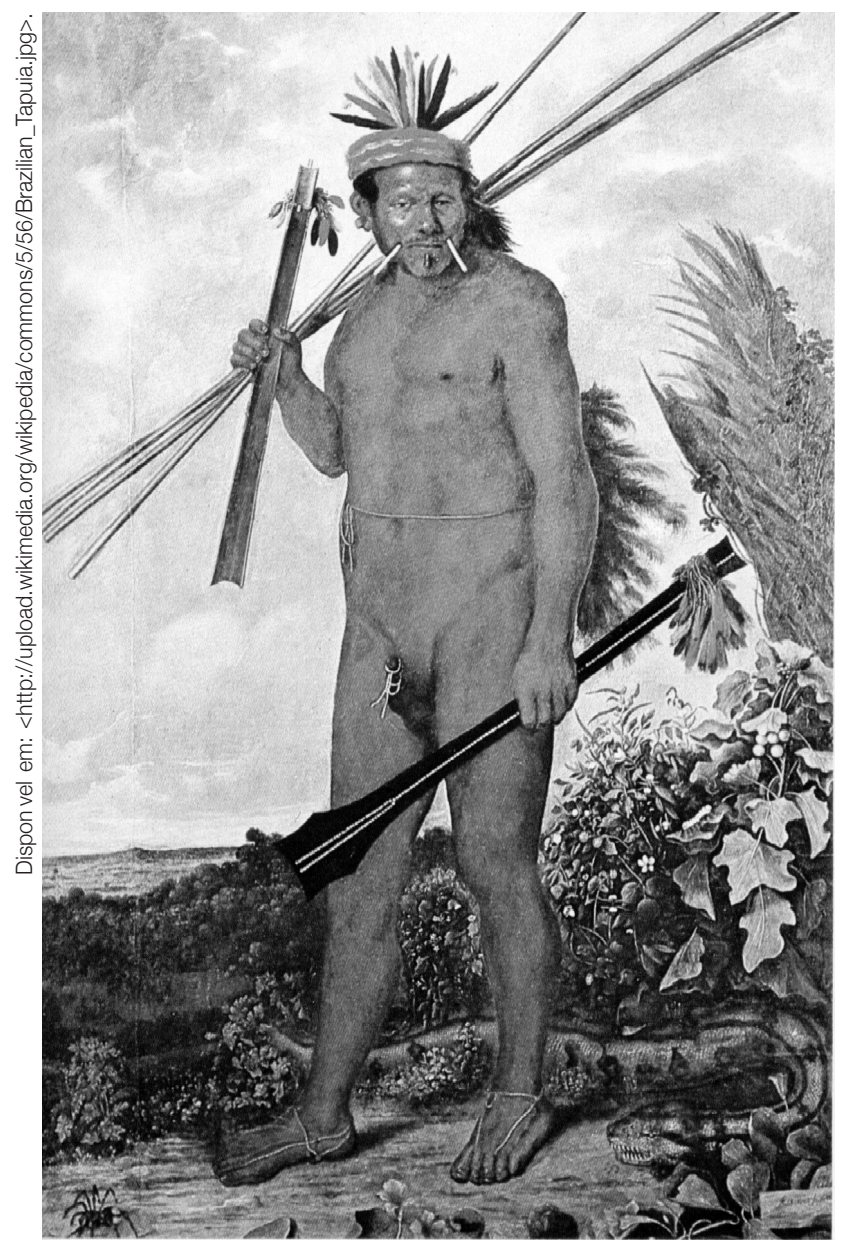

ndio Tapuia, de Albert Eckhout.

O famoso pintor, que retratou os nativos e mesti os do Brasil, chegou ao Nordeste em 1637, na comitiva do prncipe Maurcio de Nassau, em que permaneceu at 1644 . 
Imagem e etnografia - Maria Cristina Castilho Costa

\section{AS CIÊNCIAS SOCIAIS E O CONHECIMENTO DO OUTRO}

Conviver com o outro, descobrir o distante, estabelecer relações com o desconhecido tem seus custos - exige disposição, curiosidade, visão treinada e método. Essa atitude iniciada na Modernidade levou também, entre outros fatores, ao desenvolvimento das ciências humanas e sociais. A expansão europeia, a descoberta de novas culturas e de novos grupos étnicos pressionaram os filósofos a discutirem o ser humano em sua essência e diversidade. Fazê-lo de forma empírica, sistemática e baseada em conceitos racionais, e não religiosos, levou ao surgimento das ciências humanas. Como diz Foucault: "As ciências humanas, com efeito, endereçam-se ao homem, na medida em que ele vive, em que fala, em que produz" ${ }^{2}$.

$\mathrm{O}$ mesmo autor afirma que esse conhecimento se baseava menos naquilo que caracteriza exteriormente o homem, para se voltar especificamente para as manifestações psíquicas, linguísticas e culturais, ou seja, as formas pelas quais ele representa a si próprio, ou seja, para aquilo que constitui sua identidade 3 .

Por essa razão a sistematização das ciências humanas esteve intimamente ligada ao desenvolvimento da linguagem, da arte e das múltiplas formas de expressão e representação humana. Para conhecer a si mesmo e ao outro, as ciências humanas constituíram uma metodologia da qual fazia parte o diálogo e a relação próxima entre o cientista e seu objeto de pesquisa. Dessa relação surge um relato preciso, descritivo, representativo, um processo profundo de interpretação do outro, conhecido por etnografia.

Roberto Cardoso de Oliveira define a etnografia como um método científico de pesquisa empírica, pelo qual partimos do observável para chegar aos sentidos do que é observado. Para isso, leva-se em consideração tudo que é expresso pelo grupo estudado e permite construir o significado, ou seja, a interpretação do pesquisador ${ }^{4}$. Essa interpretação representa o encontro etnográfico, capaz de romper fronteiras e superar confrontos. Para isso, o autor recomenda, de forma disciplinada: olhar, ouvir, escrever...

Essa simbiose entre o ver e o descrever caracteriza a etnografia e a necessária tradução dos sentidos e da percepção em um discurso compreensivo e lógico que a torna um método aberto às demais disciplinas, assim como às artes visuais, à literatura e às práticas interpretativas e hermenêuticas, como apontou François Laplantine ${ }^{5}$.

O desenvolvimento das ciências sociais, na Modernidade, dotou o conhecimento do outro e do diferente de longos e detalhados relatos compostos por textos e imagens que procuravam estabelecer uma ponte entre o pesquisador e seu objeto de pesquisa, numa valorização cada vez maior do processo interativo como forma de apreensão e compreensão do ser humano.

\section{O DESENVOLVIMENTO DOS MEIOS DE COMUNICAÇÃO}

A Modernidade, porém, não se caracterizou apenas pelo encontro com o diferente e, consequentemente, pelo desenvolvimento das ciências humanas e sociais, mas também pelo aprimoramento dos meios de comunicação, ligando
2. FOUCAULT, Michel. As palavras e as coisas. São Paulo: Martins Fontes, 1981. p. 368

3. Ibid.

4. OLIVEIRA, Roberto Cardoso de. O trabalho do antropólogo. São Paulo: Unesp, 2000. p. 22.

5. LAPLANTINE, François. A descrição etnográfica. São Paulo: Terceira Margem, 2004. p. 10. 
os seres humanos cada vez mais compreendidos como uma grande população diversificada e em permanente expansão. Assim, os meios capazes de colocar em contato tanto os semelhantes como os diferentes passaram a competir com os textos, aquarelas e desenhos dos artistas/cientistas modernos na troca de informações sobre a realidade. Gravadores, câmeras fotográficas e, depois, videográficas desafiavam os limites da ciência e da etnografia, assim como punham em questão o que se entendia por cultura.

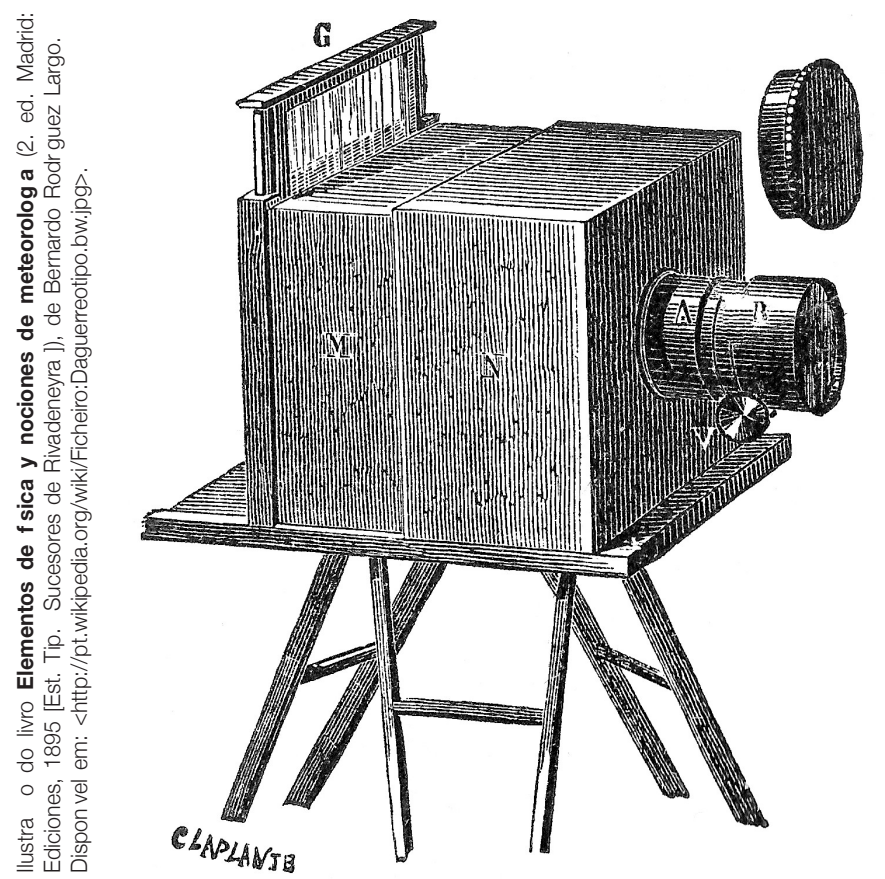

Daguerre tipo, inven o do francĺ s Louis Daguerre em 1837 e anunciada em 1839. Foi declarado pelo Governo Francl s como dom nio $p$ blico. Nesse mesmo ano um processo fotográfico distinto foi anunciado por William Henry Fox Talbot, na Inglaterra.

No século XX, a era da comunicação e da imagem colocou aos cientistas sociais o desafio de tratar de novos sistemas simbólicos e de representação, novas formas rituais e de registro do acontecer. Por outro lado, os meios e redes de comunicação reduziram as diferenças culturais, modificando os hábitos nos mais distantes cantos do planeta, e aproximaram vertiginosamente o distante.

Assim, se por um lado a fotografia e a televisão invadiam a cultura de grupos étnicos tradicionais, transformando suas visões de mundo, por outro, ao cientista abriam-se novas possibilidades de registro da vida social, assim como à divulgação dos achados científicos. No entanto, a adoção de meios de registro de sons e imagens exigia cautela, pois se reconhecia também que a tecnologia não era isenta de uma interpretação programada e automatizada do real. E assim, entre anseios e temores, os cientistas sociais foram desenvolvendo experiências com o uso dos meios de comunicação para o estudo da cultura, da sociabilidade e do comportamento humano. E o etnólogo, o antropólogo, o sociólogo, o estudioso da cultura passaram a se munir de novas formas de registro que vieram se somar ao diário de campo nas pesquisas científicas com grupos sociais. 


\section{CIÊNCIAS HUMANAS - O ESTUDO DAS IMAGENS E POR IMAGENS}

Considerados os pais da chamada Antropologia Visual, Gregory Bateson e Margareth Mead, preocupados com a gestualidade e a linguagem corporal dos grupos estudados, lançam mão da fotografia e do cinema para desenvolver seus trabalhos científicos com técnicas adequadas de descrição e análise, como definiram ${ }^{6}$. Em Bali, na década de 1930, Bateson tirou cerca de 25 mil fotos numa máquina Leica e sete mil metros de filmes de 16 $\mathrm{mm}$, com imagens que acompanham o benfeito relatório de campo elaborado por Mead.

Na mesma época, outros antropólogos utilizavam semelhantes recursos. Um deles foi Claude Lévy-Strauss, que reali-

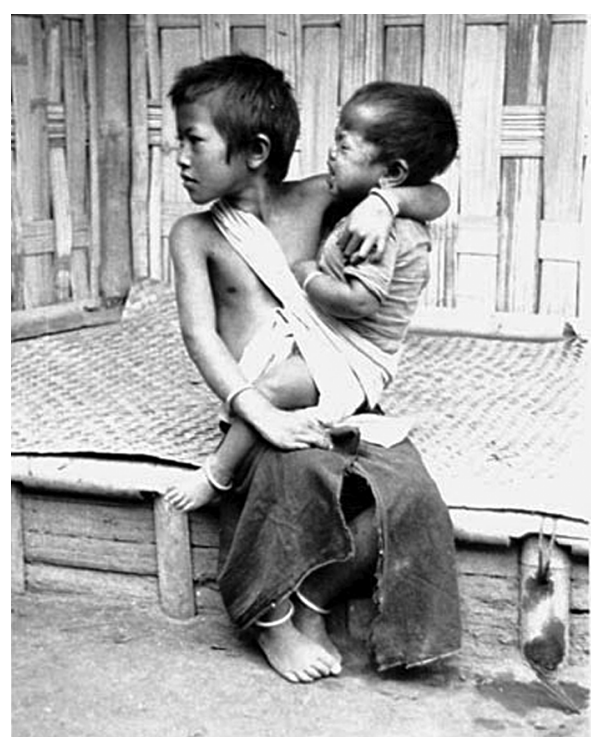

Fotografia de Gregory Bateson - Bali, 19 de agosto de 1937. zou uma reportagem fotográfica importante durante sua estada no Brasil, entre 1935 e 1937, tornando-se um pioneiro da fotografia etnográfica. Essas fotos foram, depois de décadas, publicadas em livros que o notabilizaram como fotógrafo. Pierre Verger também viajava pelo mundo com sua máquina Rolleiflex, produzindo fotografias que se tornaram clássicos da Antropologia Visual.

Defendendo essa prática do registro tecnológico pelo cientista social, Luciana Bittencourt reconhece dupla função no uso da fotografia: a primeira é a de registro da realidade e captação de informações; a segunda função é a de estimular as interpretações dos fotografados. Essas interpretações podem trazer à pesquisa "relatos adicionais que não são percebidos pelo etnógrafo em um primeiro momento"7.

Os sociólogos, embora mais reticentes que seus colegas antropólogos, também se aventuraram no campo do registro fotográfico. Roger Bastide, entre 1938 e 1948, anos em que esteve no Brasil, procurou mostrar a importância dos registros visuais para a compreensão da sociedade estudada. Mais recentemente, Pierre Bourdieu dedicou-se ao estudo das trocas simbólicas feitas por linguagens verbais e não verbais - para ele a trama dos signos refletia a das relações sociais estabelecidas.

Durante todo o século XX, historiadores, pedagogos e psicólogos também assumiram o desafio de fazer da imagem um apoio importante para o desenvolvimento teórico e científico. Mas foi nas chamadas ciências sociais aplicadas, ou ciências da comunicação, que o conhecimento profundo das técnicas e linguagens visuais transformou fotografias, cinema e vídeo em imprescindíveis recursos para o conhecimento e a interpretação da realidade e da cultura.
6. WINKIN, Yves. A nova comunicação. Campinas (SP): Papirus, 1998. p. 38.

7. BITTENCOURT, Luciana Aguiar. Algumas considerações sobre o uso da imagem fotográfica na pesquisa antropológica. In: FELDMAN BIANCO, Bela; LEITE, L. Moreira. Desafios da imagem. Campinas (SP): Papirus, 1998. p. 202. 
comunicação \& educação • Ano XV • Número 1 • jan/abr 2010

\section{IMAGEM, ETNOGRAFIA E PESQUISA EM COMUNICAÇÃO}

Não foi sem conflito que as ciências humanas e sociais foram lançando mão dos meios de comunicação para dar conta da realidade. Por um lado, a tradição científica via com desconfiança a realidade mediada por meios tecnológicos, menos flexíveis do que o olhar do cientista objetivo e treinado. Por outro, os estudos etnográficos apontavam os meios de comunicação como um dos responsáveis pelo desaparecimento de traços distintivos das culturas não ocidentais. Marc Augé afirma que as culturas tradicionais resistem menos ao poder dessacralizador das imagens veiculadas pelos meios de comunicação do que, outrora, ao poder das administrações coloniais. Segundo esse autor, estaria se processando um "desencantamento" ${ }^{8}$ do mundo entre povos tradicionais.

Mas apesar dessa visão crítica a respeito da hegemonia das imagens na cultura contemporânea, o uso dos meios de comunicação e a pesquisa científica não cessaram de se aproximar com novas experiências e propostas metodológicas. As ciências da comunicação, que têm como um de seus objetivos o estudo dessas linguagens técnicas, acabaram por desenvolver formas de investigação científica com as diferentes mídias, as quais podemos dividir nas seguintes propostas:

1 - Utilizar, como desde o século XIX se fez, a máquina fotográfica e o cinema como formas de olhar e captar o real. François Laplantine, descrevendo o método etnográfico, já o havia definido como um olhar mediado $0^{9}$ sobre o mundo. Na atualidade, essa mediação diz respeito não somente ao treino científico do olhar, mas ao uso de tecnologias de registro e representação do real. Além dos exemplos já citados, podemos mencionar as imagens produzidas por Mario de Andrade, que o ajudaram no estudo da cultura e do folclore brasileiros.

2 - Usar as imagens fotográficas, cinematográficas e videográficas como mediação na relação entre o pesquisador e a cultura estudada. Seja para perceber diferentes percepções visuais entre grupos étnicos distintos, seja para estimulá-los a interpretar registros de imagem, os meios de comunicação têm aproximado cientistas de seus objetos de estudo.

John Collier Junior, um dos pais da chamada etnofotografia, em livro que analisa essas experiências, explica que a máquina fotográfica se tornou um bom instrumento de aproximação com os grupos estudados. Como exemplo, explica que um pesquisador interessado em estudar as técnicas de pesca de um grupo de caiçaras pode acompanhar uma pescaria, registrando-a em amplo levantamento fotográfico. Este por sua vez poderá se transformar em estímulo

8. AUGÉ, Marc. A guerra dos sonhos. Campinas (SP): Papirus, 1998. p. 80.

9. LAPLANTINE, op. cit., p. 17.

10. COLLIER, John. Antropologia visual: a fotografia como método de pesquisa. São Paulo: EPU/ EDUSP, 1973. p. 18. para novos encontros e conversas em torno dos resultados obtidos. Em sua experiência etnográfica, a pergunta Você quer mostrar as fotos? pode ser a chave de entrada nos lares da tripulação pesqueira ${ }^{10}$.

3 - Analisar etnográfica e sociologicamente as imagens produzidas pelos meios de comunicação, procurando vê-las como expressão plástica e visual de um determinado autor ou grupo de autores. Esse tipo de análise exige que o cientista vá além da superficialidade e da aparência das imagens para conteúdos mais complexos que permitam revelar a intencionalidade do autor. Nesse 
Imagem e etnografia - Maria Cristina Castilho Costa

caso, as imagens são estudadas como reconstruções da realidade, resultantes da expressão simbólica e ideológica dos autores. Um dos pesquisadores a defender essa metodologia é Boris Kossoy, sociólogo e, ele mesmo, fotógrafo. Seu estudo relacionando as imagens dos cartões postais paulistas, na passagem do século XIX para o século XX, com a propaganda política que procurava divulgar a imagem de uma cidade moderna e atraente, sem vestígios da escravidão e do colonialismo, mostra as possibilidades dessa abordagem ${ }^{11}$.

George Marcus, por sua vez, é um antropólogo que analisa as trocas estéticas e científicas existentes entre os relatos etnográficos e outras manifestações artísticas e midiáticas do cinema e do videodocumentário. Ele se preocupa em identificar as produções ficcionais em que é possível perceber a apropriação da experiência etnográfica ${ }^{12}$.

4 - Estudar etnograficamente o público formado pelos meios de comunicação de massa. É a chamada etnografia das audiências, que permite entender as relações que as pessoas estabelecem com as linguagens midiáticas como relações culturais e, portanto, passíveis da mesma metodologia de investigação. Diversos trabalhos têm merecido reconhecimento nesta vertente. Gladis Linhares analisou como os índios Terena veem telenovelas ${ }^{13}$, e Maria Immacolata Vassalo de Lopes estudou a recepção da telenovela em famílias de diferentes estratos sociais ${ }^{14}$.

Em qualquer dessas direções para as quais a pesquisa científica se volte, percebe-se a crescente determinação por parte da ciência de fazer uso de experiências culturais mediadas na compreensão da realidade e do ser humano em especial.

\section{O OUTRO E A ATUALIDADE}

O homem da atualidade continua a ser um explorador curioso e aventureiro que, tendo ultrapassado as Colunas de Hércules, jamais colocou limites em sua expansão pelo planeta e para fora dele. Continua impulsionado pelas conquistas, guerras, busca do lucro ou do desenvolvimento tecnológico e científico. É motivado também por novas descobertas e pelos deslocamentos sociais e geográficos. Mas, paradoxalmente, questões ligadas à identidade e à alteridade, assim como às diferenças culturais e de vida existentes na sociedade, continuam exigindo dele novas explicações. A globalização, a comunicação em rede e a distância e o progressivo desbravamento do planeta vêm introduzindo novas concepções de tempo e espaço na vida humana, assim como têm promovido diferentes formas de sociabilidade, aproximação e relacionamento. Dessa forma, se, por um lado, hábitos, crenças e estilos de vida se tornam cada vez mais parecidos em diversas partes do mundo, saber quem somos e de quem estamos próximos ou distantes torna-se um desafio estimulante e uma necessidade.

É por isso que a etnografia, passados tantos séculos de sua prática pelos cientistas sociais, volta a ser um modelo de investigação promissor, capaz de nos colocar diante de nós mesmos e dos outros, permitindo desvendar novas formas de sociabilidade e comunicação. Essa etnografia, entretanto, incorpora
11. KOSSOY, Boris. Realidades e ficções na trama fotográfica. São Paulo: Ateliê, 1999.

12. MARCUS. George E. A estética contemporânea do trabalho de campo na arte e na antropologia: experiências em colaboração e intervenção. In: BARBOSA, Andréa; CUNHA, Edgar Teodoro da; HIKIJI, Rose Satiko Gitirana. Imagem-conhecimento. Campinas (SP): Papirus, 2009.

13. LINHARES, Gladis. A televisão no imaginário dos terena. Campo Grande (MS): Uniderp, 2000.

14. LOPES, Maria Immacolata Vassalo de; BORELLI, Silvia H. Simões; RESENDE, Vera da Rocha. Vivendo com a telenovela: mediações, recepção e teleficcionalidade. São Paulo: Summus, 2002. 
toda a experiência dos etnógrafos com a imagem e faz dela um elemento decisivo da compreensão da sociedade contemporânea, também conhecida como era da imagem.

O pesquisador contemporâneo deverá buscar identidades, indivíduos e coletividades em um mundo ainda não desbravado, com relações humanas complexas mediadas pelas tecnologias e meios de comunicação. Essa busca resultará na ampliação cada vez mais sem limites daquilo que muitos autores, tão precisamente, chamam de visão de mundo, ou seja, a compreensão das relações complexas existentes entre mundo objetivo e subjetividade. A imagem será, cada vez mais, o elemento que o orientará nessa exploração.

\section{REFERÊNCIAS BIBLIOGRÁFICAS}

AUGÉ, Marc. A guerra dos sonhos. Campinas (SP): Papirus, 1998.

BITTENCOURT, Luciana Aguiar. Algumas considerações sobre o uso da imagem fotográfica na pesquisa antropológica. In: FELDMAN BIANCO, Bela; LEITE, L. Moreira. Desafios da imagem. Campinas (SP): Papirus, 1998.

COLLIER, John. Antropologia visual: a fotografia como método de pesquisa. São Paulo: EPU/Edusp, 1973.

FOUCAULT, Michel. As palavras e as coisas. São Paulo: Martins Fontes, 1981.

KOSSOY, Boris. Realidades e fiç̧ões na trama fotográfica. São Paulo: Ateliê, 1999.

LAPLANTINE, François. A descrição etnográfica. São Paulo: Terceira Margem, 2004.

LINHARES, Gladis. A televisão no imaginário dos terena. Campo Grande (MS), Uniderp, 2000.

LOPES, Maria Immacolata Vassalo de; BORELLI, Silvia H. Simões; RESENDE, Vera da Rocha. Vivendo com a telenovela: mediações, recepção e teleficcionalidade. São Paulo: Summus, 2002.

MARCUS. George E. A estética contemporânea do trabalho de campo na arte e na antropologia: experiências em colaboração e intervenção. In: BARBOSA, Andrea; CUNHA, Edgar Teodoro da; HIKIJI, Rose Satiko Gitirana. Imagem-conhecimento. Campinas (SP): Papirus, 2009.

OLIVEIRA, Roberto Cardoso de. O trabalho do antropólogo. São Paulo: Unesp, 2000 .

WINKIN, Yves. A nova comunicação. Campinas (SP): Papirus, 1998. 